\title{
Magnitude of Medication Administration Error and Associated Factors Among Nurses Working in Madda Walabu University Goba Referral Hospital, Bale Zone Oromia Region, Southeast Ethiopia
}

Hiwot Fikadu Haile

Madda Walabu University

Abulie Melku Takele ( $\square$ abuletakele@yahoo.com )

Madda Walabu University

Addisu Gemechu Abdi

Madda Walabu University

Research article

Keywords: Medication, Medication Error, Medication Administration, Nurses

Posted Date: November 18th, 2020

DOl: https://doi.org/10.21203/rs.3.rs-107351/v1

License: (c) (i) This work is licensed under a Creative Commons Attribution 4.0 International License.

Read Full License 


\section{Abstract}

Background: Administration of medication is the primary responsibility of nurses. Medication errors occurring during the drug administration process can be attributed to a variety of safety effects, ranging from undetected errors to prolonged hospital stays, discomfort and death.

Objective: To determine the magnitude of the medication administration error and associated factors among nurses working at Madda Walabu University Goba Referral Hospital, Bale Zone Oromia Region, South East Ethiopia.

Methods: A facility-based cross-sectional study was conducted at Madda Walabu University Goba Referral Hospital Inpatient Department from February to March, 2020. The study included three hundred ninety-eight medication interventions administered by 89 inpatient unit working nurses during the study period. Data were collected using a pre-tested, structured questionnaire and drug administration assessment using a checklist. Data were analyzed using SPSS version 22 and Frequency, Percentage, Means and SD were analyzed for descriptive analysis. COR and AOR were calculated to see the association of independent variables and uncontrolled hypertension at $95 \% \mathrm{Cl}$ and $\mathrm{p}$-value $<0.05$ was considered statistically significant.

Result: The magnitude of the medication error was 248 (62.3\%). The most common type of medication error was wrong documentary evidence $(53.5 \%)$, followed by wrong time $(39.2 \%)$ and wrong dosage (28.\%). Variables that were substantially associated with medication administration error include work experience of nurses $0-4$ years $(\mathrm{AOR}=10.8,95 \% \mathrm{Cl}(4.5-25.86), 5-9$ years of service $(\mathrm{AOR}=4.05,95 \% \mathrm{Cl}$ (1.47-11.715), nurses 1-6 $(\mathrm{AOR}=0.36,95 \% \mathrm{Cl}(0.17-0.76)$ nurses $7-10(\mathrm{AOR}=0.45,95 \% \mathrm{Cl}(0.21-0.96)$ route IV of medication $(A O R=0.13,95 \% \mathrm{Cl}(0.03-0.60)$ and IM route $(A O R=.0 .12,95 \% \mathrm{Cl}(0.02-0.74)$ at p-value $<0.05$.

Conclusion: Medication administration error was highly prevalent. Work experience, nurse to patient ratio and route of medication administration were statistically significant factors associated with occurrence of medication administration error. The preparation of nurses and the hospital staff profile would be helpful in minimizing mistakes in the administration of drugs.

\section{Background}

According to the United States (US) National Coordinating Council for Medication Error Reporting and Prevention (NCCMERP) in 2017 defined medication error as any preventable event that may cause to inappropriate medication use or patient harm while the medication is in the control of the health care professional, patient, or consumer (NCC-MERP, 2017). Medication errors have become common causes of harm to patients with up to $6.5 \%$ of patients in clinical settings affected and it causing serious public health threats (Alsulami \& Zayed, 2013). 
Medication administration errors are a common subtype of medication error and one of the most common types of adverse events in hospital-accepted patients and the most common cause of preventable death (WHO, 2018; Feleke, Mulatu \& Yesmaw, 2015). The United States National Coordinating Council for Medication Error Reporting and Prevention (NCCMERP, 2018 ) found that $38 \%$ of the medical error occurred in the hospital during the medication administration process (NCCMERP, 2018). Patient morbidity and mortality are the major consequences of these medication administration errors (MAEs). It may also have cost implications for patients, families and health care providers due to prolonged hospital stays and psychological impact since errors undermine public confidence in health care services (Baraki et al., 2018).

Medication administration errors are usually committed by nurses because the primary responsibility of the nurse is to administer the medication, with between $16 \%$ and $40 \%$ of the time spent by nurses in MA (Bifftu et al ., 2016; Dumo, 2012; Westbrook et al., 2011). Nurses are the last safety check in the chain of events in the medication administration process and are the last guarantee of patient well-being (Ojerinde \& Adejumo, 2014). Nurses should therefore avoid this error by adhering to the rights of medication administration (RMA) and reporting to MAEs (Flynn et al ., 2012; Kim et al., 2011; Ojerinde \& Adejumo, 2014)

Miscarriages of all kinds are well examined throughout much of the developed world and the outcome has shown that the magnitude of MAEs among nurses is still high (Adam, 2018; WHO, 2018). In developing countries, especially in East Africa, MAE is common and the error rate ranges from 9.4 to $80 \%$ of all medication administrations (Alsulami, Conroy \& Choonara, 2013). Similarly, it has also been reported in Ethiopia that the prevalence of MAE is still high. For example, studies in 3 public hospitals in Tigray and 3 tertiary hospitals in Addis Ababa have shown 62.7\% and 68.1\% prevalence, respectively (Baraki et al. 2018, Adam 2018). These mean that MAE is a real concern and a real threat to patient safety. However, the issue has rarely been investigated and scarce in Ethiopia (Mekonnen et al., 2017, Alemu, Belachew \& Yimam, 2017, Agbor, 2016).

\section{Statement of the Problem}

At every step, trained nurses have the potential to make a mistake in their everyday nursing practices, with some degree of danger to patient safety. The complexity of the medication administration process is such that errors can occur at one, several, or even at all stages between prescription and administration (Rodriguez-Gonzalez etal., 2012).

Medication errors are the most common type of medical error occurring in hospitals and ranked among the top ten causes of death worldwide (Mahajan, 2011). Medication errors, especially those made during the administration of drugs, were highly prevalent. Each medication process and each patient had at least one type of Medication administration (Feleke, Mulatu \& Yesmaw, 2015). 
Medication error has a significant impact on patients in terms of morbidity, mortality, adverse drug event, and increased length of hospital stay. It also increases costs for physicians and healthcare systems (Popescu, Currey \& Botti, 2011). In the United States, for example, between 44,000 and 98,000 hospitalized patients die annually from preventable medical errors, with more than 7,000 deaths due to drug errors (Cohen, 2007). In addition, the cost of medication error in England is 98.5 million pounds per year (Elliott et al ., 2018). Similarly, Dabaghzadeh, et al. (2013) in a study of drug error in a large teaching hospital in Iran showed that $19 \%$ of drug administration contained at least one mistake. $44.5 \%$ of nurses made the most reported mistakes, mostly during the drug administration process (63.6\%). Most of these drug-related errors, leading to poor patient recovery, decreased client satisfaction and death, and other forms of harm to patients (Redley \& Botti, 2012).

Patients living in developing countries experienced as twice as many drug-related problems as those living in developed countries (WHO, 2017). According to a systematic review of adverse drug events and medication failures in African hospitals, $8.4 \%$ of patients experienced any alleged adverse drug incident at hospital admission, while $2.8 \%$ of patients admitted to hospital due to adverse drug events (Mekonnen, Alhawassi, McLachlan \& Jo-anne, 2017). In general, medication administration errors attributed to being the most common cause of disability and death throughout the world (Feleke, Mulatu \& Yesmaw, 2015). However, there are only a few relevant studies on drug administration errors in developing and transitional countries, particularly in Africa. In developing countries such as Ethiopia with educational, economic and skilled labor problems, the issue is one of the least studied and neglected health problems (Adam, 2018).

Therefore, assessing the magnitude and associated factors of MAE will produce information that can be used by program managers and stakeholders in the planning and interventions of medication administration errors. As far as the knowledge of the researcher, the magnitude of medication administration error and contributing factors in the study area not studied. Moreover, since the researcher have been working in Madda Walabu University Goba Referral Hospital, observing medication administration errors made by nurses in many instants and patients and families of patients also usually compiling the actuality of the error. Hence, this study was aimed assess the magnitude and contributing factors of medication administration error among nurses working in Madda Walabu University Goba Referral Hospital of Bale Zone Oromia Region, South East Ethiopia.

\section{Methods And Materials}

\section{Study area and period}

The study was conducted at Madda Walabu University Goba Referral Hospital, located in the Bale Area of the Oromia Province, in the South East of Ethiopia. It is located $445 \mathrm{~km}$ away from the capital city of Addis Ababa in Ethiopia. MWUGRH is the only major referral and teaching hospital in South East Ethiopia. The hospital has four main departments, namely: Pharmacy, Surgery, Obstetrics and Gynacology, and Pedatrics with more than 160 beds. The hospital provides services to approximately 20,000 inpatients and 150,000 outpatients each year. There are 108 General Practitioner Physicians, 15 Specialist Doctors with different specialties, 130 nurses, 120 other health professionals of different 
qualifications and experiences and 486 supporting staff during the study period (Goba Referral Hospital Human Resources Office, 2020). In addition, Madda Walabu University Goba Referral Hospital provides a number of community services, including emergency 24-hour pharmacy and delivery services. It also offers physiotherapy, counseling, antennatal treatment, TB and ART services. The study was conducted from 30 February to 12 March 2020.

\section{Study design and population}

Institutional cross-sectional research design was used. All nurses working at Madda Walabu University Goba Referral Hospital were the source population for the research. Both nurses working in the Madda Walabu University Goba Referral Hospital and engaging in the medication administration in the inpatient department during the study period were members of the study population. Nurses specifically involved in the administration of medications and operating in the inpatient department at the time of the study were involved. Nurses that are on an annual and parental leave and/or sick at the time of study, undergoing onthe-job training and nurses who are not specifically involved with inpatient care were excluded.

\section{Sampling procedure and sample size}

A total of 398 medications which were administered by 89 nurses to patients in the inpatient department at the time of the study were the sample size of the study.

\section{Study variables}

The dependent variable for the stdy was an error in the administration of medication.

The independent variables were Socio-demographic characteristics (sex, age, marital status, educational status, and where nurses attend their previous educational), work-related factors (work experience, on job refreshment training, period in the clinical unit, route of medication), institutional factors (availability of reporting systems of medication errors, availability of written guidance for medication administration, availability of marked medication shelf, availability of medication preparation room) and environmental factor (interruption while preparing or administering medication, change of medication administration).

\section{Conceptual definition of terms}

In order to have common understanding the following definition of terms were used

Medication error (ME) is broadly defined as any error in the prescribing, dispensing, or administration of a drug (Barber, Rawlins \& Franklin, 2003)

Medication administration error (MAE)A medication error (time, dose, Unauthorized, Missed drug, Wrong patient, Documentation error, Wrong medication) that occurs While the time of administering IV, IM, SC, and PO medication to the patient by the nurse. (Baraki et al., 2018, Feleke et al., 2015) 
Wrong medication: medication administered to the patients that were not on the patient's medication chart (Feleke et al., 2015).

Wrong dose: when the medication dose, strength or quantity given is different from that of prescribed (Baraki et al., 2018).

Wrong time: administration of medications 30 minutes earlier or later from its scheduled administration time (Feleke et al., 2015).

Wrong route: the actual route of medication administration differs from the recommended route of medication administration (Feleke et al., 2015).

Wrong patient: when a medication of one patient is wrongly given to another patient (Baraki et al., 2018).

Documentation error: medication that is administered to the patient but not documented in medication administration record sheet (Adam, 2018). Or medication that is administered to the patient incorrectly or incompletely documented in medication administration record sheet.

Unauthorized drug error: Medication administered was not authorized by the prescriber (Feleke et al., 2015).

Missed drug error: failures to administer a prescribed medication while the drug available at the patient bedside (Feleke et al., 2015).

\section{Data collection instruments}

In order to achieve the study objective and to gather the relevant data, an observational checklist and a structured self-administered questionnaire were used. The instruments were adapted from already existing studies (Adam, 2018; Baraki et al., 2018; Feleke, Mulatu \& Yesmaw, 2015). The observational checklist contains eight components and it used to gather data by observing nurses while medicating patients to assess the incidence and types of MAE.

The self-administration questionnaire was used to assess the socio-demographic characteristics of nurses and other variables that generate MAE. The method consists of three sections : the first section contains five questions on the socio-demographic characteristics of the participants; the second section contains eight questions on work and organizational factors; and the final section contains two questions on the reporting of drug error (Adam, 2018; Baraki et al . , 2018; Feleke, Mulatu \& Yesmaw, 2015). The observational checklist and self-administration questionnaire were pre-tested on 20 nurses and rectified on 40 doses prior to the main data collection at Robe Regional Hospital, which is not included in the analysis and the constraining factors. Cronbach's alpha coefficient of the data collection instrument was $5-007=0.83$.

\section{Data collection procedures}


In data collection, six data collectors (BSc nurses) with prior experience in data collection and two supervisors were recruited. Prior to the actual work, intensive training was given to data collectors and supervisors for two days on the study objective, questionnaire and checklist style, evaluation procedures and reporting methods to supervisors and principal investigators. Written documentation has been prepared and delivered to data collectors and supervisors to ensure that everyone provides the same direction and information. Data collection took place from 30 February to 12 March 2020.

Data on the administration of drugs were collected through a self-administered standardized questionnaire and observation checklist by personally observing nurses in charge of the administration of drugs. In addition, after observation, the data on the recorded observation compared to the physicians are ordered by reference to the patient chart. After ensuring their willingness to participate in the study, the self-administered questionnaire was distributed among the study population. The anonymity of the participants was maintained by informing them not to enter their names on the questionnaire.

\section{Data Quality Assurance}

To ensure the quality of the data, the questionnaire was adapted from the previous study and four experts (two clinical nurses and two nurse academics) revised the tools to check their validity. In addition, the questionnaire and observation checklist were pre-tested at Robe General Hospital prior to the actual data collection. Data collectors and supervisors have been recruited on the basis of their experience in data collection and research. In addition, the main investigator was trained for two days on the objective of the study, instrument and data collection procedures.

Health professionals (infirmaries) who were observed during the administration of drugs to each patient were informed of the work prior to the start of data collection, but the entire purpose of the study was not disclosed to ensure that the findings were impartial. The data collectors checked the completeness of the questionnaires and the checklists, and finally the supervisors and the main investigators checked the questionnaire. During the data collection period, the supervisors and the main investigators followed up on a continuous basis.

\section{Data analysis}

After the questionnaires and completed observation checklists were returned, reviewed for completeness and marked, SPSS version 22.0 was used to enter, clean and analysed data. Descriptive statistics such as frequencies, percentages, mean and standard deviations have been calculated and defined. To see the relationship of dependent and independent variables, a bivariate and multivariate logistic regression analysis has been carried out. The odds ratio with $95 \% \mathrm{Cl}$ and p-value at 0.05 is used to declare statistically significant association. The results of the study were presented using statistics, tables, graphs and texts.

\section{Ethical considerations}


Ethical clearance was obtained from Madda Walabu University Goba Referral Hospital School of Health Sciences Department of Nursing Ethics Committee. The official letter was sent to the hospital. A letter of approval was then received from the Chief Clinical Officer of the Hospital. The study was conducted after permission was granted by the hospital administrators. In addition, all research participants have been advised of the intent of the research and their right to participate and have the right to terminate at any time if they do not wish to continue the study without violating any of the benefits they may receive. Respondents were assured of confidentiality of the information obtained. The respondents' verbal consent was gained by asking whether or not they would like to participate. Respondents were not required to mention their name and other personal identifiers, such as telephone numbers.

\section{Results}

\section{Socio-demographic characteristics of nurses observed}

A total of 89 nurses were reported for this study while administering medications. The average age of the nurses was 30.9 years with \pm 6.5 SDs. More than one-third of them (39.3\%) were aged $25-29$ years. More than half of the $54(60.7 \%)$ nurses were male. In terms of educational qualification, $62(69.7 \%)$ of them had a Bachelor of Science degree in nursing. Eighty-one (91\%) of the nurses surveyed had graduated from government teaching institutions. Approximately half of them (48.3\%) had work experience of less than five years (Table 1). 
Table 1

Socio-demographic characteristics of nurses observed in the study in Madda

Walabu University Goba Referral Hospital, South East Ethiopia

\begin{tabular}{|c|c|c|c|}
\hline Characteristics & Category & Frequency & $\%$ \\
\hline \multicolumn{4}{|l|}{ Age in year } \\
\hline & $\leq 24$ & 10 & 11.2 \\
\hline & $25-29$ & 35 & 39.3 \\
\hline & $30-34$ & 20 & 22.5 \\
\hline & $\geq 35$ & 24 & 27 \\
\hline \multicolumn{4}{|l|}{ Sex } \\
\hline & Male & 54 & 60.7 \\
\hline & Female & 35 & 39.3 \\
\hline \multicolumn{4}{|c|}{ Educational status } \\
\hline & Diploma & 27 & 30.3 \\
\hline & Degree & 62 & 69.7 \\
\hline \multicolumn{4}{|l|}{ Marital status } \\
\hline & Single & 31 & 34.8 \\
\hline & Married & 56 & 62.9 \\
\hline & Divorced & 2 & 2.2 \\
\hline \multicolumn{4}{|l|}{ Graduated from } \\
\hline & Governmental institution & 81 & 91 \\
\hline & Private & 8 & 9 \\
\hline \multicolumn{4}{|c|}{ Work experience in years } \\
\hline & $<5$ & 43 & 48.3 \\
\hline & $5-9$ & 6 & 6.7 \\
\hline & $10-14$ & 25 & 28.1 \\
\hline & $>=15$ & 15 & 16.9 \\
\hline
\end{tabular}

Characteristics of patients who were included during the observation

A total of 212 patients were seen while nurses were administering their medication at Madda Walabu University Goba Referral Hospital during the study period. More than half of 124 (58.5\%) of patients 
receiving the drugs were male. The mean age of patients taking drugs was 26.34 years with an SD of \pm 21.28 years and more than half of them were 122 years of age $(57.5 \%)$ and older. More than one-fourth $61(28.7 \%)$ were admitted to the Medical Station, followed by Paediatrics Station 55 (25.9\%) and Surgical Station 49 (23.1\%) (Table 2).

Table 2

Characteristics of patients Madda Walabu University Goba Referral Hospital, inpatient departments, South East Ethiopia, 2020

\begin{tabular}{|c|c|c|c|}
\hline Characteristics & Category & Frequency & $\%$ \\
\hline \multicolumn{4}{|l|}{ Sex of patients } \\
\hline & Male & 124 & 58.5 \\
\hline & Female & 88 & 41.5 \\
\hline \multicolumn{4}{|l|}{ Age of patents } \\
\hline & $<18$ years & 90 & 42.5 \\
\hline & $>=18$ years & 122 & 57.5 \\
\hline \multicolumn{4}{|c|}{ Admission ward of patients } \\
\hline & Medical ward & 61 & 28.7 \\
\hline & Surgical ward & 49 & 23.1 \\
\hline & Paediatrics & 55 & 25.9 \\
\hline & Emergency & 16 & 7.5 \\
\hline & $\mathrm{NICU}$ & 31 & 14.6 \\
\hline
\end{tabular}

\section{Distribution of medication administration across work and organizational related characteristics}

A total of 398 drug administration services were observed in the Madda Walabu University Goba Referral Hospital inpatient unit during the study period. Approximately one-fourth, 102 (25.6\%) of drug administration was found in Medical Ward followed by Paediatrics 101 (25.4\%). Approximately two thirds of $279(70.1 \%)$ of the drug administration reported were carried out during the daytime change. More than one third of $149(37.4 \%)$ of the medication administered by nurses took care of more than 10 patients per day. Approximately two thirds of mediation administrations observed $271(68.1 \%)$ were performed by nurses who had not undergone any medication administration training. Three hundred and twenty $(80.4 \%)$ of the observed MA did not have an interruption while administering drugs. Approximately 303 $(76.1 \%)$ of the medication administered was administered in the clinics where the preparation room for the medication was not available. A large majority of 389 (97.7\%) of the drugs were prepared in rooms where the labeled drug administration shelf is not available. Three hundred and thirty-three (83.7\%) drugs were prepared in a ward that did not have guidelines for the administration of drugs (Table 3). 
Table 3

Medication administration distribution across work and organizational related characteristics, Madda Walabu University Goba Referral Hospital, inpatient departments, South East Ethiopia, 2020

\begin{tabular}{|c|c|c|c|}
\hline Characteristics & Category & Frequency & $\%$ \\
\hline \multicolumn{4}{|l|}{ Working place } \\
\hline & Medical & 102 & 25.6 \\
\hline & Surgical & 76 & 19.1 \\
\hline & Paediatrics & 101 & 25.4 \\
\hline & Emergency & 33 & 8.3 \\
\hline & $\mathrm{NICU}$ & 86 & 21.6 \\
\hline \multicolumn{4}{|c|}{ Duration in specific unit } \\
\hline & $0-6$ month & 289 & 72.6 \\
\hline & 7-12 month & 62 & 15.6 \\
\hline & $>12$ month & 47 & 11.8 \\
\hline \multicolumn{4}{|c|}{ Shift of medication administration } \\
\hline & Day Shift & 279 & 70.1 \\
\hline & Night Shift & 119 & 29.9 \\
\hline \multicolumn{4}{|c|}{ Nurses to patient ratio } \\
\hline & $1-6$ & 134 & 33.7 \\
\hline & $7-10$ & 115 & 28.9 \\
\hline & $>10$ & 149 & 37.4 \\
\hline \multicolumn{4}{|l|}{ Training } \\
\hline & Yes & 127 & 31.9 \\
\hline & No & 271 & 68.1 \\
\hline \multicolumn{4}{|c|}{ Ever reporting error } \\
\hline & Yes & 20 & 5.0 \\
\hline & No & 378 & 95.0 \\
\hline \multicolumn{4}{|l|}{ If no reasons } \\
\hline & Fear of reporting & 49 & 12.3 \\
\hline & Workload & 33 & 8.3 \\
\hline
\end{tabular}




\begin{tabular}{|c|c|c|c|}
\hline Characteristics & Category & Frequency & $\%$ \\
\hline & Unavailability of reporting system & 296 & 74.4 \\
\hline \multicolumn{4}{|c|}{ Faced Interruption during medication administration } \\
\hline & Yes & 78 & 19.6 \\
\hline & No & 320 & 80.4 \\
\hline \multicolumn{4}{|c|}{ Availability of medication preparation room } \\
\hline & Yes & 95 & 23.9 \\
\hline & No & 303 & 76.1 \\
\hline \multicolumn{4}{|c|}{ Availability of labelled medication administration shelf } \\
\hline & Yes & 9 & 2.3 \\
\hline & No & 389 & 97.7 \\
\hline \multicolumn{4}{|c|}{ Availability of medication administration guideline } \\
\hline & Yes & 65 & 16.3 \\
\hline & No & 333 & 83.7 \\
\hline
\end{tabular}

\section{Types of the observed drugs and their administration}

More than two thirds of $278(69.8 \%)$ of the 398 drug administrations observed were Antibiotics. As far as the route of drug administration is concerned, 339 (85.2\%) of the drugs observed were administered through the Intravenous Route followed by the Intramuscular Route $33(8.3 \%)$. More than half of the 237 $(59.5 \%)$ drugs were administered twice daily with respect to the frequency of drug administration (Table 4). 
Table 4

The observed drugs, route and frequency of administration, Madda

Walabu University Goba Referral Hospital, inpatient departments,

Southeast Ethiopia

\begin{tabular}{|c|c|c|c|}
\hline Characteristics & Category & Frequency & $\%$ \\
\hline \multicolumn{4}{|c|}{ Type of medication } \\
\hline & Antibiotics & 278 & 69.8 \\
\hline & Analgesics & 63 & 15.8 \\
\hline & Anti diabetic drugs & 18 & 4.5 \\
\hline & Gastrointestinal drugs & 17 & 4.3 \\
\hline & Anticoagulant drugs & 10 & 2.5 \\
\hline & Diuretics drugs & 12 & 3.0 \\
\hline \multicolumn{4}{|c|}{ Route of administration } \\
\hline & Intra venous & 339 & 85.2 \\
\hline & Intra muscular & 33 & 8.3 \\
\hline & Subcutaneous & 26 & 6.5 \\
\hline \multicolumn{4}{|c|}{ Frequency of administration per day } \\
\hline & Once & 3 & .8 \\
\hline & Two times & 237 & 59.5 \\
\hline & Three times & 107 & 26.9 \\
\hline & Four times & 51 & 12.8 \\
\hline
\end{tabular}

\section{Magnitude and type of medication administration error}

Eight types of drug error were observed in this study, namely: wrong time, wrong patient, wrong dose, wrong route, unauthorized drug, missed drug, wrong route, and incorrect documentation that occurred at the time of the nurse's administration of the medication to the patient was used to identify a drug error. Medication administration error was recorded when a single or combination of the above mentioned errors occurred while administering the medication(s) to the patient.

The prevalence of drug error from a total of 398 drugs administered was 248 (62.3\%) (Fig. 1). Out of 248 medication errors committed, 61 (25.4\%) had only one type of error, $171(68.9 \%)$ had 2 types of error, and $16(6.5 \%)$ had 3 and more than 3 types of drug error. The most widely perpetuated form of drug error was incorrect documentation 213 (53.5\%) followed by incorrect time 156 (39.2\%). Incorrect dose administration is the third common $112(28.1 \%)$ drug administration and error (Table 5; Fig. 2). These 
errors were committed by 72 (80.8\%) nurses from 89 nurses who participated in the study. Of these, more than half of the $38(52.8 \%)$ nurses made a mistake at least three times during the stated period.

Table 5

Types of medication administration errors observed in inpatient departments of Madda Walabu University Goba Referral Hospital, inpatient department, Southeast Ethiopia

\begin{tabular}{|llll|}
\hline Variables & Category & Frequency & $\%$ \\
\hline Wrong medication & Yes & 3 & 0.8 \\
Wrong dose & No & 395 & 99.2 \\
\hline Wrong route & Yes & 112 & 28.1 \\
& No & 286 & 71.9 \\
\hline Wrong time & Yes & 5 & 1.5 \\
& No & 393 & 98.5 \\
\hline Wrong patient & Yes & 156 & 39.2 \\
& No & 242 & 60.8 \\
\hline Wrong documentation & Yes & 1 & 0.3 \\
& No & 397 & 99.7 \\
\hline Un authorized drug & Yes & 9 & 53.5 \\
& No & 389 & 97.7 \\
\hline Missed drug & Yes & 52 & 13.1 \\
& No & 346 & 86.9 \\
\hline
\end{tabular}


Table 6

Types of medication administration errors observed in the inpatient departments of Madda Walabu University Goba Referral Hospital, South East Ethiopia, 2020.

\section{S. Some observed examples \\ No}

1 The observer observed while Insulin given intradermal instead of subcutaneous route.

2 Most medications in the morning were being given after 7:00 am instead of 6:00 am

3 The observer observed a nurse while she was giving Plasil IV instead of Tramadol IV

$4 \quad$ Most of the nurses did not document after administration of the drug.

5 The observer observed while Ampicillin was given to a 28 years old although the order sheet reads as Cloxacillin.

$6 \quad$ Metronidazole IV medication mostly missed at 2 PM (especially during the weekends)

$7 \quad$ Instead of administering $2 \mathrm{~g}$ of Ceftriaxone, the nurse administered $1 \mathrm{~g}$.

Usually at paediatric ward, the nurse did not calculate the exact doses of medication.

8 The observer observed while Ceftriaxone was given to an 43 years old male even after the physician ordered to discontinue the medication

\section{Factors Associated With Medication Administration Errors}

Bivariable logistic regression was used to determine the correlation of each independent variable to the dependent variable. In this study, the variables that were significantly associated with the dependent variable in Bivariable logistic regression were the work experience of nurses, period in a specific unit of nurses per month, medication preparation, nurse-to - patient ratio, availability of medication guideline and route of medication administration.

One of the variables that demonstrated association with MAE in bivariate logistic regression was the nurse's work experience. Nurses with work experience $<5$ years and $5-9$ years were 23.6 times $\mathrm{COR}=$ 23.6, $95 \% \mathrm{Cl}(11.60-48.052)$ and 5.9 times $\mathrm{COR}=5.9,95 \% \mathrm{Cl}(2.59-13.68)$ were more likely to make a medication administration mistake compared to those with work experience $>=15$. Nurses who worked in a specific ward for a period of $0-6$ months is 6.7 -fold $\mathrm{COR}=6.7,95 \% \mathrm{Cl}(3.37-13.37)$ more likely to make a medication administration error compared to those who worked in a specific ward for a span of more than 12 months.

Medicines managers who did not receive medication training were approximately 4.63 times higher risk of MAE than those who received COR training $=4.63,95 \% \mathrm{Cl}(2.95-7.26)$. Respondents who had a nurseto - patient ratio of $1-6$ and $7-10$ were $87 \% \mathrm{COR}=0.13,95 \% \mathrm{Cl}(0.07-0.22)$ and $72 \% \mathrm{COR}=0.28(0.16-$ 0.51 ) less likely to make an error compared to a nurse-to - patient ratio of $>10$. Availability of the drug administration guideline was also found to be factors correlated with MAE in bivariate logistic regression, with medications prepared at a location where the medication administration guide was approximately 2,385 times $\mathrm{COR}=2,385,95 \% \mathrm{Cl}(1,39-4,0884)$ more than their counterparts. Medication administered 
via IV route and IM route was $81 \% \mathrm{COR}=0.197,95 \% \mathrm{Cl}(0.058-0.669)$ and $78 \% \mathrm{COR}=0.22895 \% \mathrm{Cl}$, (0.056-0.923) less likely to be MAE than SC route (Table 7). 
Table 7

Bivariate logistic regression analysis of factors associated with MAE in Madda Walabu University Goba Referral Hospital, inpatient departments, South East Ethiopia, 2020.

\begin{tabular}{|c|c|c|c|c|}
\hline \multirow[b]{2}{*}{ Characteristics } & \multirow[b]{2}{*}{ Category } & \multicolumn{2}{|c|}{$\begin{array}{l}\text { Medication } \\
\text { administration error }\end{array}$} & \multirow[b]{2}{*}{$\operatorname{COR}(95 \% \mathrm{Cl})$} \\
\hline & & Yes & No & \\
\hline \multirow[t]{4}{*}{ Work experience of nurses } & $<5$ & 170 & 20 & $\begin{array}{l}23.6(11.60- \\
48.052)\end{array}$ \\
\hline & $5-9$ & 30 & 14 & $\begin{array}{l}5.9(2.59- \\
13.68)\end{array}$ \\
\hline & $10-14$ & 30 & 66 & $1.2(0.63-2.5)$ \\
\hline & $>=15$ & 18 & 50 & 1 \\
\hline \multirow[t]{3}{*}{$\begin{array}{l}\text { Duration in specific unit of nurses in } \\
\text { month }\end{array}$} & $\begin{array}{l}0-6 \\
\text { month }\end{array}$ & 208 & 81 & $\begin{array}{l}6.7(3.37- \\
13.37)\end{array}$ \\
\hline & $\begin{array}{l}7-12 \\
\text { month }\end{array}$ & 27 & 35 & $\begin{array}{l}2.01(0.89- \\
4.54)\end{array}$ \\
\hline & $\begin{array}{l}>12 \\
\text { month }\end{array}$ & 13 & 34 & 1 \\
\hline \multirow[t]{2}{*}{ Training on MA } & Yes & 48 & 79 & 1 \\
\hline & No & 200 & 71 & $\begin{array}{l}4.63(2.95- \\
7.26)\end{array}$ \\
\hline \multirow[t]{3}{*}{ Nurses to patient ratio } & $1-6$ & 54 & 80 & $\begin{array}{l}0.13(0.07- \\
0.22)\end{array}$ \\
\hline & $7-10$ & 69 & 46 & $\begin{array}{l}0.28(0.16- \\
0.51)\end{array}$ \\
\hline & $>10$ & 125 & 24 & 1 \\
\hline \multirow[t]{2}{*}{$\begin{array}{l}\text { Presence of medication administration } \\
\text { guideline }\end{array}$} & Yes & 29 & 36 & $\begin{array}{l}2.385(1.39- \\
4.088)\end{array}$ \\
\hline & No & 219 & 114 & 1 \\
\hline \multirow[t]{5}{*}{ Route of medication administration } & IV & 204 & 135 & $0.197(0.058-$ \\
\hline & & & & $0.669)$ \\
\hline & IM & 21 & 12 & $0.228(0.056-$ \\
\hline & & & & $0.923)$ \\
\hline & SC & 23 & 3 & 1 \\
\hline
\end{tabular}

To control the effect of the confounding variables, the variables which showed association in bivariate logistic regression at $p$-value $<0.05$ were taken into multivariate logistic regression. Multivariable logistic 
regression analysis identified the work experience as positively associated, while nurses identified the patient ratio and route of administration as negatively associated with the dependent variable.

Nurses with work experience of $0-4$ years and $5-9$ years were 6.0 times $(A O R=6.0,95 \% \mathrm{Cl}(4.5-15.08)$ and 4.05 times $(A O R=4.05,95 \% \mathrm{Cl}(1.47-11.715)$ higher than those with work experience of more than 15 years. Another factor that showed association with MAE was the ratio of nurse to patient. Nurses with a nurse-to - patient ratio of $1-6$ and $7-10$ were $64 \%(A O R=0.36,95 \% \mathrm{Cl}(0.17-0.76)$ and $55 \%(A O R=$ $0.45,95 \% \mathrm{Cl}(0.21-0.68)$ less likely to make an error compared to nurse-to - patient ratios of $>10$. Route of drug administration was also found to be one of the predictors of MAE. Medications administered via IV route and IM route were $87 \%$ and $88 \%$ less likely to have MAE than those administered via SC route with $(\mathrm{AOR}=0.13,95 \% \mathrm{Cl}(0.03-0.60)$ and $(\mathrm{AOR}=.0 .12,95 \% \mathrm{Cl}(0.02-0.74)$ respectively (Table 8). 
Table 8

Bivariate and multivariable logistic regression analysis of factors associated with MAE in Madda Walabu University Goba Referral Hospital, inpatient departments, South East Ethiopia, 2020.

\section{Medication administration}

error

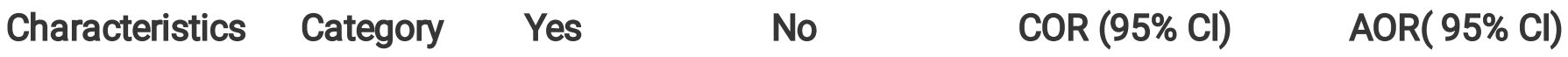

Work experience of nurses

\begin{tabular}{lllll}
$<5$ & 170 & 20 & $\begin{array}{l}23.6(11.60- \\
48.052)\end{array}$ & $\mathbf{6 . 0 ( 4 . 5 - 1 5 . 0 8 ) *}$ \\
\hline $5-9$ & 30 & 14 & $5.9(2.59-13.68)$ & $\begin{array}{l}4.05(1.47- \\
11.715) *\end{array}$ \\
\hline $10-14$ & 30 & 66 & $1.2(0.63-2.5)$ & $1.0(0.38-2.6)$ \\
\hline$>15$ & 18 & 50 & 1 & 1
\end{tabular}

Duration in specific unit of nurses in month

\begin{tabular}{lcccc}
$\begin{array}{l}0-6 \\
\text { month }\end{array}$ & 208 & 81 & $6.7(3.37-13.37)$ & $2.19(0.76-6.34)$ \\
\hline $\begin{array}{l}7-12 \\
\text { month }\end{array}$ & 27 & 35 & $2.01(0.89-4.54)$ & $1.4(0.45-4.41)$ \\
\hline $\begin{array}{l}>12 \\
\text { month }\end{array}$ & 13 & 34 & 1 & 1 \\
\hline
\end{tabular}

Training on

MA

$\begin{array}{lllll}\text { Yes } & 48 & 79 & 1 & 1 \\ \text { No } & 200 & 71 & 4^{\prime} 63(2.95-7.26) & 1.78(0.82-3.87)\end{array}$

Nurses to patient ratio

\begin{tabular}{lllll}
\hline $1-6$ & 54 & 80 & $0.13(0.07-0.22)$ & $\mathbf{0 . 3 6}(0.17-0.76)$ * \\
\hline $7-10$ & 69 & 46 & $0.28(0.16-0.51)$ & $\mathbf{0 . 4 5 ( 0 . 2 1 - 0 . 6 8 )}$ * \\
\hline$>10$ & 125 & 24 & 1 & 1
\end{tabular}

Medication administration Guideline

\begin{tabular}{lllll} 
Yes & 29 & 36 & $2.385(1.39-$ & $1.25(0.53-2.9)$ \\
& & & 4.088 & \\
\hline No & 219 & 114 & 1 & 1
\end{tabular}

Route of medication administration 


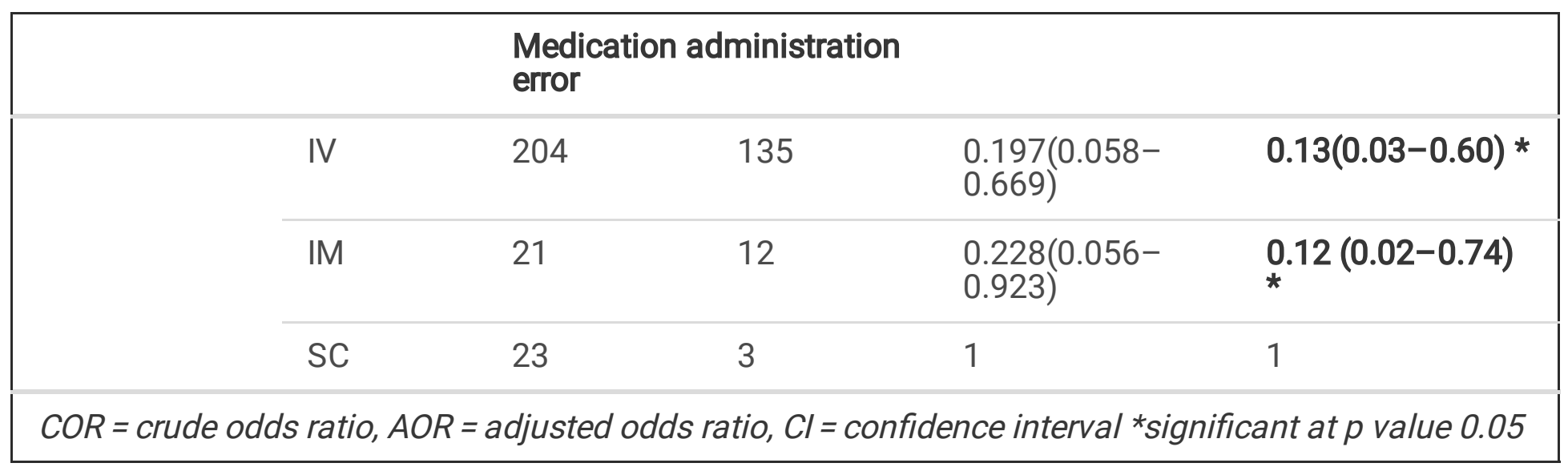

\section{Discussion}

The findings are discussed in this section in line with the research questions that have guided this research. The opinions and observations of the research participants are discussed in relation to previous research findings in other settings. International and local scholarly sources have also been used to support the issues under consideration. This approach is believed to provide readers with the opportunity to examine some degree of association between the findings of this study and other studies. As a reminder to readers, the main objective of the study, as stated at the outset, is to determine the magnitude of the medication administration error and associated factors among nurses at work in the study area.

Findings from this study showed that 248 (62.3\%) errors in the administration of drugs were of significance. This finding is relatively consistent with the study conducted in seven hospitals in South Korea, a hospital in Turkey, and a public hospital in Ethiopia (Tigray) MAE of $63.6 \% 61.7 \%$ and $62.7 \%$ respectively (Keers, Williams, Cooke \& Ashcroft, 2013; You et al., 2015; Baraki et al ., 2018).

Whereas the results of this study contradict study reports on medication administration mistake in Vietnam 39.1\% (Nguyen et al., 2015), in France 27.6\% (Berdot et al ., 2012), in Egypt Ain Shams University Hospital 37.8\% (Al Tehewy et al., 2016), in Ghana tertiary care hospital adult emergency department 27.2\% (Franklin Acheampong ARTaBPA, 2015). This disparity may be due to the difference in the number of hospitals and the number of clinical facilities under investigation. Similarly, some of the above studies have been conducted in relatively well-developed countries with better administration of drugs with an integrated prescribing and recording method.

Similarly, the result of this study is higher than the study conducted in Ethiopia at Felege Hiwot Referral Hospital Inpatient Clinic, which was 56.4\% (Feleke, Mulatu, Yesmaw, 2015) and in Jimma University Hospital ICU, which was $51.8 \%$ (Agalu, Ayele, Bedada \& Woldie, 2012). The possible explanation may be that the educational level, the work experience of nurses, the MAE training, the ratio of nurses to patients, the availability of standards and facilities in the above-mentioned hospitals are most likely to be better.

However, the findings of this study are lower than those of three teaching hospitals in South Korea, Jimma University Hospital Pediatric Unit, two public hospitals in Southern Ethiopia and three public tertiary hospitals in Addis Ababa, $69.6 \%, 89.9 \%, 71 \%$ and $68.1 \%$ of nurses, respectively, made errors in the 
administration of drugs (Berdot et al ., 2012; Feleke \& Girma, 201\%). The plausible explanation for this disparity may be due to variations in the number and form of hospitals and study methods. In particular, the research in Addis Ababa Tertiary Hospitals relies mainly on self-reported respondents (questionnaire) than on observation.

In this study, out of a total of 248 medication administration errors recorded by nurses, $61(15.3 \%)$ had only one type of MAE, $171(43.0 \%)$ had 2 types of MAE, and $16(4.0 \%)$ had more than 3 types of MAE. This result may provide insight into the fact that many nurses make errors two times and more than two times in each drug administration phase. The findings of this study can be attributed to low work experience of nurses, lack of MAE preparation, high workload (nurse to patient ratio), lack of guidance and facilities. This result is reasonably consistent with a study in the Felege Hiwot referral hospital of 360 medication administration procedures in which $42(11.9 \%)$ had only one form of medication administration error, 112 (31.7\%) had two types of error, 168 (47.6\%) had three types of error, and the remaining $31(8.8 \%)$ had more than three types of drug administration.

Wrong documentation (53 per cent) was the most common form of MAE found in this report. This result suggests that more than half of the medications prescribed to the patient have not been recorded in the drug administration record sheet. Similarly, studies conducted at the University Hospital of Egypt, Felege Hiwot Referral Hospital of Ethiopia and two Southern Hospitals in Ethiopia have shown that the key type of medical error made by nurses is $90.6 \%, 87.5 \%$ and $85.4 \%$, respectively, of record error (Al Tehewy et al ., 2016; Alemu, Belachew \& Yimam, 2017; Feleke, Mulatu \& Yesmaw, 2015). These research has shown that nurses are ineffective in drug administration reporting. This could be due to lack of knowledge about the necessity of documentation.

Similarly, in addition to incorrect documentation error, incorrect time error (38.9\%) was the most common type of MAE observed in this study. In Ethiopia, failure to administer drugs at the right time was a commonly reported type of drug error. This may be related to a lack of knowledge among nurses about time management. Consistent with this result, studies in Ghana and South Africa have shown that the form of medication errors (36.7\%) and (43\%) were commonly reported (Franklin Acheampong ARTaBPA, 2015; Blignaut, Coetzee, Klopper \& Ellis, 2017).

Similarly, study conducted in Ethiopia in Tertiary Hospitals in Addis Ababa, Felege Hiwot Referral hospital, Jimma University ICU, Jimma university pediatrics ward and two Southern Ethiopia hospitals wrong time error was 57.8\%, 53.6\%, 30.3\%, 27\% \& and 58.5\%, respectively (Adam, 2018; Alemu, Belachew \& Yimam, 2017; Feleke, Mulatu \& Yesmaw, 2015; Feleke \& Girma, 2010; Agalu, Ayele, Bedada \& Woldie, 2012).

The finding of this study identifies that work experience of nurses was significantly associated with medication administrations errors. Studies conducted in Tertiary Hospitals in Addis Ababa, Felege Hiwot Referral hospital and emergency department of southern Iran Hospital indicated that there is a significant association between work experience of nurses and medication administrations errors (Adam, 2018; Alemu, Belachew \& Yimam, 2017; Vazin, Zamani \& Hatam, 2014). The reasonable explanation can be that medication administration is one of the nurse's practices that improve with experience. Nurses with 
more years of work experience have greater knowledge and skills related to medication administration. Thus, the possibility of making an error minimized with better work experience because they may get much familiar with different types of medications.

This study also showed that nurse to patient ratio was significantly associated with medication administrations errors. Nurses working in situation where the nurse to patient ratio of 1-6 and 7-10 were less likely to make an error as compared to nurses working in situation where the nurse to patient ratio greater than 10. This finding agrees with the study conducted in Ghana tertiary care hospital that shows the occurrence of MAE was significantly associated with number of patients under the nurse's care (Franklin Acheampong ARTaBPA, 2015). Similarly, a study carried out in Felege Hiwot Referral Hospital revealed that nurse to patient ratio of 7-10 and nurse to patient ratio greater than 10 was found to be significantly associated with medication administration error (Feleke, Mulatu \& Yesmaw, 2015). This can be explained by the fact that as workload or number of medication administered by nurses increases nurses are usually exhausted and the possibility of making an error would be high.

Furthermore, in this study route of medication administration was found to be one of the predictors of MAE. Medications, which were administered through IV route and IM route, were less likely to have MAE than a medication which was administered through SC route. This finding is partly supported by studies conducted in France that showed medication errors were significantly associated with administration route (error was higher for administrations by injection) (Berdot et al., 2012).

\section{Conclusion}

The magnitude of medication administration error in Madda Walabu University Goba referral hospital was highly prevalent. This show that Nurses most often make medication administration error during administering medications in the patient care unit, Documentation error followed by wrong time and wrong dose was the most common types of medication administration errors. Nurse's work experience, nurse to patient ratio and route of medication administration were significantly associated with medication administration. Nurses' capacity building and supportive supervision were required to avert the medication administration errors.

\section{Limitation of the study}

Potential care providers bias during data collection using observational method (social desirability bias). And as the study was cross-sectional it does not allow to conclude cause and effect relationship between the variables.

\section{Acronyms}




\begin{tabular}{ll} 
BCMA & Bar Coded Medication Administration \\
\hline ICU & Intensive Care Unit \\
\hline IV & Intravenous \\
\hline MA & Medication Administration \\
\hline MAE & Medication Administration Error \\
\hline ME & Medication Error \\
\hline NCCMERP & National Coordinating Council for Medication Error Reporting Prevention \\
NGO & Non-Governmental Organization \\
\hline NHS & National Health Service \\
\hline RMA & Rights of Medication Administration \\
\hline US & United States \\
\hline UK & United Kingdom \\
\hline WHO & World Health Organization
\end{tabular}

\section{Declarations}

\section{Ethical considerations}

Ethical clearance was obtained from Madda Walabu University Goba Referral Hospital School of Health Sciences Department of Nursing Ethical Committee. The official letter was submitted to the hospital. Then a letter of permission was secured from the Chief Clinical Director Office of the hospital. The study was conducted after the administrators of the hospital gave their permission. Moreover, all participants of the study were informed about the purpose of the study and their right to participate and have the right to terminate at any time if they don't like to continue in the study without infringement of any of the benefit they could get. Respondents were assured about the confidentiality of information collected. Verbal consent of the respondents was obtained by asking whether they want to participate or not. The respondents were not required to mention their name and other personal identifiers such as phone number.

\section{Consent for publication}

All the information used for this study was collected with the consent of participates of the study. And all the authors have read the manuscript and have consented to publish it this journal.

\section{Data availability}


The data for this study is available with the authors and can be accessed based on the request from the concerned body.

\section{Funding}

Funding agencies do not have role in the publication of the paper.

\section{Competing interest}

The authors declare that they do not have conflict of interest.

\section{Authors' contribution}

Hiwot Fikadu have conceived and designed the study, performed the data analysis and write up of the final result. Abulie Takele participated in designing the study, performed the statistical analysis, writing the results and discussion and prepared the manuscript. And Addisu Gemech participated in designing the study, performed the statistical analysis and writing the results

\section{Acknowledgements}

We would like to thank Madda Walabu University Goba Referral Hospital and Department of Nursing for giving me this opportunity and necessary support during this study. My sincere and heartfelt gratitude goes to staff members of Madda Walabu University Goba Referral Hospital for their boundless support and cooperation during data collection.

\section{References}

1. Adam W. Assessments of Magnitude and Contributing Factors of Medication Administration Error among Nurses in Tertiary Hospitals, Addis Ababa, Ethiopia. MA Thesis, Addis Ababa University. 2018.

2. Agalu A, Ayele Y, Bedada W, Woldie M. Medication administration errors in an intensive care unit in Ethiopia. International archives of medicine. 2012;5(1):15.

3. Ahmadizar F, Soleymani F, Abdollahi M. Study of drug-drug interactions in prescriptions of general practitioners and specialists in Iran 2007-2009. Iran J Pharm Res. 2011;10:921-31.

4. Al Tehewy M, Fahim H, Gad NI, El Gafary M, Rahman SA. Medication Administration Errors in a University Hospital of Egypt. Journal of Patient Safety. 2016;12(1):34-39.

5. Al-Sarawan,. Nurses perceptions medication errors of main types and liding factors, and leading factors, and reporting attitudes in North West bank governmental hospitals. 2014.

6. Alemu W, Belachew T, Yimam I. Medication administration errors and contributing factors: A crosssectional study in two public hospitals in Southern Ethiopia. International Journal of Africa Nursing Sciences. 2017; 7:68-74.

7. Alsulami Z, Conroy S, Choonara I. Medication errors in the Middle East countries: a systematic review of the literature. European Journal of Clinical Pharmacology. 2013; 69(4):995-1008. 
8. Alsulami, Zayed Nama F. Medication errors in children. Ph.D. thesis, University of Nottingham. 2013.

9. Armitage, G., \& Knapman, H. Adverse events in drug administration: a literature review. Journal of Nursing Management, 2008: 11, 130-40.

10. Aspden PA, Wolcott J, Bootman JL \& Cronenwett L. Committee on Identifying and Preventing Medication Errors. National Academies Press. 2006; 24(2):89-95.

11. Ayuk Agbor G. A Literature Review of Medication Errors in the United States of America. 2016.

12. Baraki Z, Abay M, Tsegay L, Gerensea $H$, Kebede A, Teklay $H$. Medication administration error and contributing factors among pediatric inpatient in public hospitals of Tigray, northern Ethiopia, $B M C$ Pediatrics, 2018; 18:321.

13. https://doi.org/10.1186/s12887-018-1294-5.

14. Berdot S, Sabatier B, Gillaizeau F, Caruba T, Prognon P, Durieux P. Evaluation of drug administration errors in a teaching hospital. BMC Health Services Research. 2012;12(1):60.

15. Bifftu BB, Dachew BA, Tiruneh BT, Beshah DT. Medication administration error reporting and associated factors among nurses working at the University of Gondar referral hospital, Northwest Ethiopia, 2015. BMC Nursing. 2016; 15(1):43.

16. Blignaut AJ, Coetzee SK, Klopper HC, Ellis SM. Medication administration errors and related deviations from safe practice: An observational study. J Clin Nurs, 2017; 1-14.

17. Cheraghi, M., Nikbakhat N. A, Nejad, M. E, Salari, A., \& Ehsani K. K.(2012). Medication errors among nurses in Intensive Care Unites (ICU). Journal of Mazandaran University Medical Sciience, 21, 115119.

18. Cohen. MR. Preventing Medication Errors. The New England Journal of Medicine, 2007.

19. Choo J, Hutchinson A \& Bucknall T (2010) Nurses' role in medication safety. Journal of Nursing Management, 18, 853-861.

20. Dabaghzadeh, F., Rashidian, A., Torkamandi, H., Alahyari, S., Hanafi, S., Farsaei, S., \& Javadi, M. Medication errors in an emergency department in a large teaching hospital in Tehran. IranJournal of Pharmacology Research, 2013: 12(4), 937-942.

21. Dedefo MG, Mitike AH, Angamo MT. Incidence and determinants of medication errors and adverse drug events among hospitalized children in West Ethiopia. BMC pediatrics. 2016;16(1):81.

22. DHS/Safety, health, and independence for all Oregonians, 2017

23. Dumo AMB. Factors affecting medication errors among staff nurses: basis in the formulation of the medication information guide. IAMURE International Journal of Health Education. 2012; 1(1):88-149

24. Elliott R, Camacho E, Campbell F, Jankovic D, Martyn St James M, Kaltenthaler E, et al. Prevalence and economic burden of medication errors in the NHS in England. Rapid evidence synthesis and economic analysis of the prevalence and burden of medication error in the UK. 2018.

25. Fathi A, Hajizadeh M, Moradi K, Zandian H, Dezhkameh M, Kazemzadeh S, et al. Medication errors among nurses in teaching hospitals in the west of Iran: what we need to know about prevalence, types, and barriers to reporting. Epidemiology and Health. 2017; 39. 
26. Feleke SA, Mulatu MA, Yesmaw YS. Medication administration error: magnitude and associated factors among nurses in Ethiopia. BMC Nursing. 2015; 14(1):53.

27. Feleke $Y$, Girma B. Medication administration errors involving pediatric in-patients in a hospital in Ethiopia. Tropical Journal of Pharmaceutical Research. 2010;9(4).

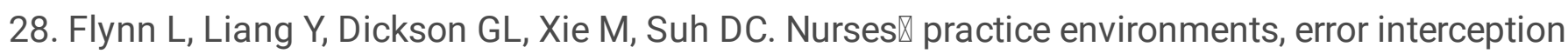
practices, and inpatient medication errors. Journal of Nursing Scholarship. 2012;44(2):180-186.

29. Franklin Acheampong ARTaBPA. Medication Administration Errors in an Adult Emergency Department of a Tertiary Health Care Facility in Ghana. Patient saf. 2015.

30. Girma B, Feleke Y. Medication Administration Errors Involving Paediatric In-Patients in a Hospital in Ethiopia. Trop J Pharm Res. 2010;9(4):401-7.

31. Grasso, B. C., Genest, R., \& Jordan, C. W. (2013). Use of chart and record reviews to detect medication errors in a state psychiatric hospital. Psychiatric Services, 54(5), 677-81.

32. Güneş ÜY, Gürlek Ö, Sönmez M. Factors contributing to medication errors in Turkey: nurses' perspectives. Journal of Nursing Management. 2014; 22(3):295-303.

33. Härkänen, M., Turunen, H., Saano, S., \& Vehviläinen-Julkunen, K. (2013). Medication errors: What hospital reports reveal about staff views? Nursing Management, 19(10), 32-37.

34. Jennings BM, Sandelowski M \& Mark B (2011). The nurse's medication day. Qualitative Health Research, 21, 1441-1451.

35. Karna K, Sharma S, Inamdar S, Bhandari A. Study and evaluation of medication errors in a tertiary care teaching hospital-a baseline study. Int J Pharm Sci. 2012; 4(5):587-593.

36. Keers RN, Williams SD, Cooke J, Ashcroft DM. Prevalence and nature of medication administration errors in health care settings: a systematic review of direct observational evidence. Annals of Pharmacotherapy. 2013;47 (2):237-256.

37. Kim KS, KWON SH, KIM JA, Cho S. Nurses $\rrbracket$ perceptions of medication errors and their contributing factors in South Korea. Journal of Nursing Management. 2011;19(3):346-353.

38. Kozier B. Fundamentals of nursing: concepts, process, and practice. Pearson Education; 2010.

39. Mahajan RP. Medication errors: can we prevent them? BJA. 2011;107(1):3-5.

40. Mahajan RP. Medication errors: can we prevent them? British Journal of Anaesthesia. 107 (1): 3-5. 2011.

41. Mansouri A, Ahmadvand A, Hadjibabaie M, Kargar M, Javadi M, Gholami K. Types and severity of medication errors in Iran; a review of the current literature. DARU Journal of Pharmaceutical Sciences. 2013;21(1):49.

42. Mekonnen AB, Alhawassi TM, McLachlan AJ, Jo-anne EB. Adverse Drug Events and Medication Errors in African Hospitals: A Systematic Review. Drugs-Real World Outcomes. 2017:1-24.

43. MERP N. National Coordinating Council for Medication Error Reporting and Prevention (NCC-MERP). Taxonomy of Medication Errors. available at: http://wwwnccmerporg/about-medication-errors. October 12, 2017. 
44. Montesi G and Lechi A. (2009) Prevention of medication errors: detection and audit. British Journal of Clinical Pharmacology, 6:651-655.

45. NHS England., 2014. Patient Safety Alert. Stage Three: Directive, Improving medication error incident reporting and learning. Available at: http:// www.england.nhs.uk/wp content/uploads/2014/03/psasup-info-med-error.pdf [accessed 19 October 2019].

46. Negash G, Kebede Y, Hawaze S. Medication errors in the adult emergency unit of a tertiary care teaching hospital in Addis Ababa. Arch Pharm Pract. 2013; 4(4):147-50.

47. NCCMERP,Online at https://mpra.ub.uni-muenchen.de/89644/MPRA Paper No. 89644, posted 24 Oct 2018 06:39 UTC, 2018.

48. Nguyen HT, Nguyen TD, van den Heuvel ER, Haaijer-Ruskamp FM, Taxis K. Medication errors in Vietnamese hospitals: prevalence, potential outcome and associated factors. PloS one. 2015;10(9):e0138284.

49. Ojerinde AC, Adejumo P. Factors associated with medication errors among health workers in University College Hospital, Nigeria. Journal of Nursing and Health Science distribution system. Pharm World Sci. 2014;25(3):112-7.

50. Parihar M, Passi GR. Medical errors in paediatric practice. Indian pediatrics. 2008;45(7):586.

51. Pham J., Story J., \& Hicks R., Shore, D., Morlock, L., Cheung, D., Kelen, G., Pronovost, P. National study on the frequency, types, causes, and consequences of voluntarily reported emergency department medication errors. Journal of Emergency Medicine, 2011: 40(5), 485-492.

52. Popescu A, Currey J, Botti M. Multifactorial influences on and deviations from medication administration safety and quality in the acute medical/surgical context. Worldviews Evidence-Based Nurses. 2011;8(1):15-24.

53. Redley, B., \& Botti, M. Reported medication errors after introducing an electronic medication management system, medication safety, and quality. Journal of Clinical Nursing, 2012:22, 579-589, doi: 10.1111/j.1365-2702.2012.04326.

54. Rodriguez-Gonzalez CG, Herranz-Alonso A, Martin-Barbero ML, Duran-Garcia E, Durango-Limarquez MI, Hernandez-Sampelayo P, et al. Prevalence of medication administration errors in two medical units with automated prescription and dispensing. J Am Med Informatics Assoc 2012; 19 (1):72-8.

55. Salmasi S, Khan TM, Hong YH, Ming LC, Wong TW. Medication errors in South East Asian countries: A systematic review. PLoS One 2015; 10 (9):e0136545.

56. Schmidt CE, Bottoni T. Improving medication safety and patient care in the emergency department. $J$ Emerg Nurs. 2003;29:12-6.

57. SERVICES ODOH. Six Rights of Safe Medication Administration. DHS/Safety, health, and independence for all Oregonians. 2017.

58. Sheet. F. Medical errors: Not just a headline: National partnership for women and families. 2009:1.

59. Stratton KM, Blegen MA, Pepper G, Vaughn T. Reporting of medication errors by pediatric nurses. $J$ Pediatr Nurs. 2004; 19(6):385-92. 
60. Stoppler, M., (2006). The most common medication errors. Retrieved from http://www.medicinenet.com/script/main/art.asp?articlekey=55234.

61. Taufiq S. Prevalence and Causes of Wrong Time Medication Administration Errors: Experience at a Tertiary Care Hospital in Pakistan. Canadian Journal of Nursing Informatics. 2015;10(1-2).

62. Vazin A, Zamani Z, Hatam N. Frequency of medication errors in an emergency department of a large teaching hospital in southern Iran. Drug, Healthcare and Patient Safety. 2014;6:179.

63. World Health Organization Global Patient Safety. Medication without harm. WHO, 2017.

64. Yle, Medication errors becoming an epidemic. Available from: http:// ylefi/ uutiset/ medical errors becoming epidemic/6438319Yle. 2013.

65. You MA, Choe MH, Park GO, Kim SH, Son YJ. Perceptions regarding medication administration errors among hospital staff nurses of South Korea. International Journal for Quality in Health Care. 2015;27(4):276-283.

\section{Figures}

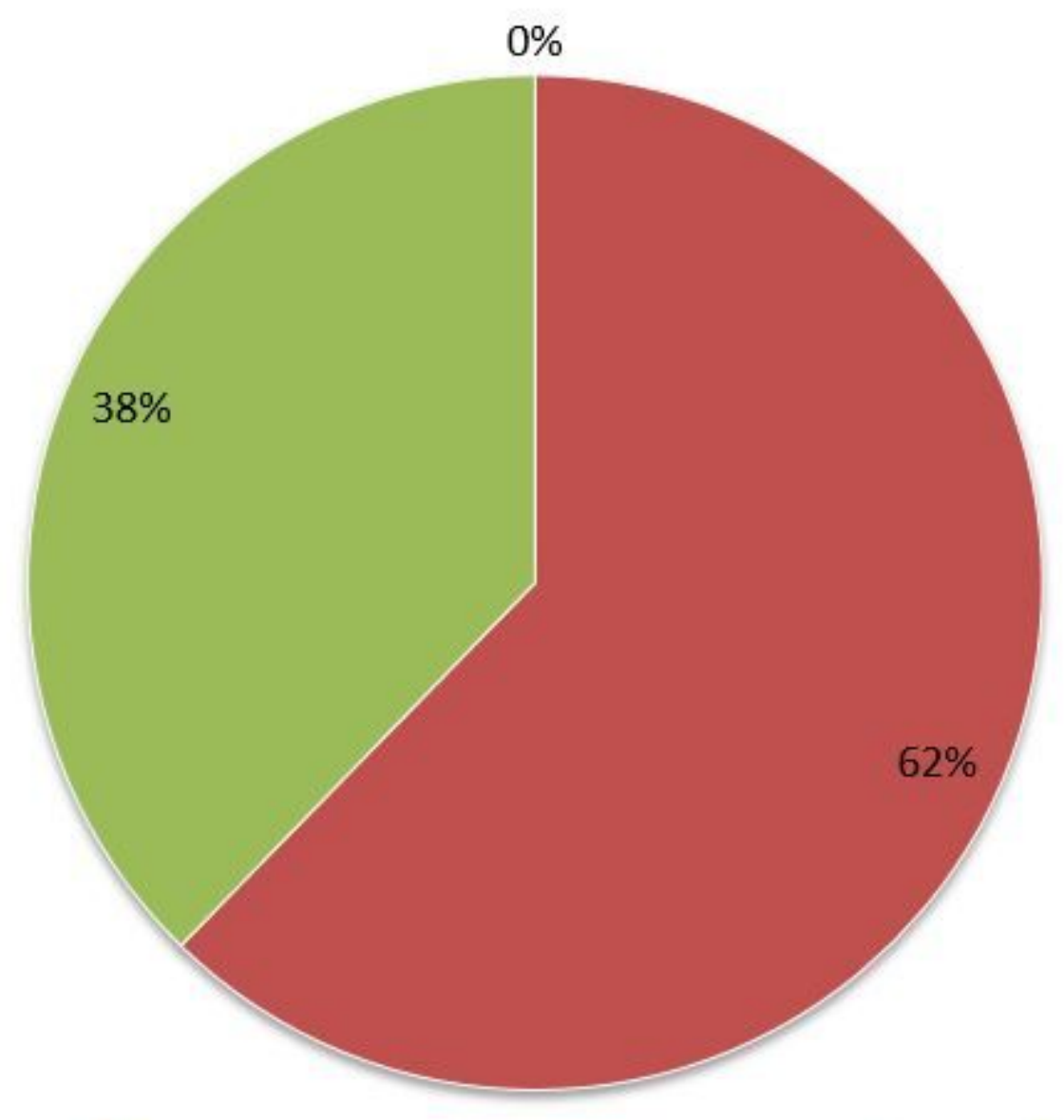

घedication administration error $\square$ Yes $\approx$ No 
Figure 1

Magnitude of medication administration errors in Madda Walabu University Goba Referral Hospital, inpatient departments, South East Ethiopia

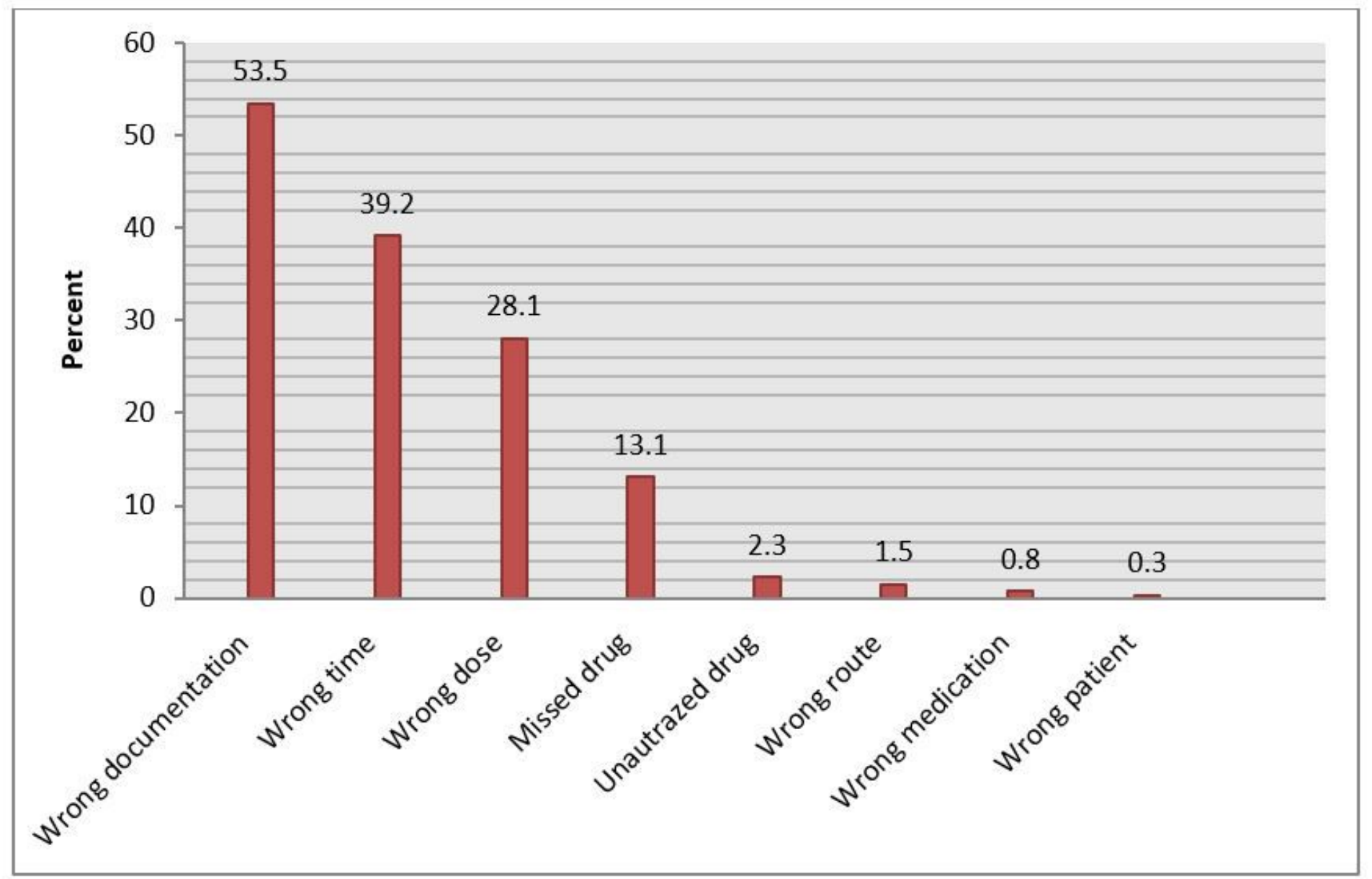

\section{Figure 2}

Types of medication administration errors in Madda Walabu University Goba Referral Hospital, inpatient departments, South East Ethiopia, 2020 ( $n=398)$. 